\title{
An Invitation: Examining Academically High-Achieving Students with Learning Disabilities in Higher Education
}

\author{
Amy Domenique Gadsden \\ University of Alberta, Canada
}

\begin{abstract}
Students with learning disabilities (SLD) are increasingly present in post-secondary environments in Canada [9]. Current research has examined fragmented components of their lived experiences such as factors that facilitate success or failure at school, personal attributes and characteristics. The existing studies remain somewhat reductive in their scope, failing to address or holistically capture the multi-faceted dimensions of the disability experience, and often framing it in terms of at-risk or deficit models of disability. This paper will provide a brief review of the existing research in this area which reveals both the important contributions of studies to date and the opportunity for new kinds of methods and questions in accessing the complex experiences of SLD in school. As such, the paper will also highlight the author's current research efforts to continue to examine these themes more holistically.
\end{abstract}

\section{Introduction}

Students with learning disabilities (SLD) face a variety of barriers while pursuing their education throughout their lifetime [7]. These barriers, which are multiple and complex, range from ineffective instruction for those with learning disabilities (LD), to a lack of accommodations (i.e., adaptations such as additional time to complete assignments and the availability of assistive technology) [8]. Such factors have been shown to adversely influence students' development, thus impacting their overall education and life outcomes [4].

These problems continue at the post-secondary level, where, despite the growth of inclusive policies, pedagogy, and research agendas, SLD continue to experience disparate achievement and outcomes when compared to their non-disabled [9]. Such students face significant challenges and barriers specific to higher education; they may, for instance, be unable to advocate for themselves or may be unwilling to disclose their LD to access accommodations that would mitigate the impact of their LD and improve their academic achievement [8], [10]. Addressing such challenges will necessitate further methodologically diverse research in this area.

An in-depth survey of the literature reveals both the important contributions of studies to date and the opportunity for new kinds of methods and questions in accessing the complex experiences of SLD in school. The quantitative studies, first, establish discernable relationships between identified variables that affect the developmental aspects of SLD and their participation and achievement in school. This literature is particularly valuable in identifying key variables as well as establishing relationships between discernable variables that affect key outcomes. These include developmental (psychological) variables - self-concept, self-esteem, self-efficacy - and outcomes such as academic, social, emotional, health, PS participation and vocation. The qualitative research, as we have seen, looks at these established relationships, variables and seeks to address or deepen understanding of the causes, effects and mechanisms that they suggest, such as the relationship between how SLD think and feel about themselves and their established relationship to academic achievement. While the qualitative research addresses similar mechanisms, it does so by asking different questions - for example, by interrogating students' perceptions of barriers and facilitators to their achievement.

Qualitative and quantitative research thus contribute in different and complementary ways to our understanding of variables that influence how SLD experience their education. By focusing attention on meaning making, the qualitative research carries this understanding forward, bringing us closer to understanding the problem from the perspectives of SLD. By allowing students to voice their perceptions and thoughts through their stories, it offers insights into their lived experiences. As noted above, however, the existing studies remain somewhat reductive in their scope, failing to address or holistically capture the multi-faceted dimensions of the disability experience, and often framing it in terms of at-risk or deficit models of disability.

For evidence of this reductionism we may look to one group of studies discussed above - those focusing on the internal and personal factors influencing SLD. Such studies suggest that selfconcept, self-efficacy and self-esteem play critical roles in the educational achievement, degree attainment and life outcomes [4]. Analysis of these factors tends to be primarily quantitative, highly fragmented, and limited. Some quantitative studies have framed factors in binary terms (e.g., Zheng et al., 2014). Factors have been examined and understood largely as constituted in relation to something else such as non-learning disabled peers [1], [6], [7], [8], or achievement. For example, some 
scholars have associated academic self-concept with grade point average, thus limiting their questions to the relationship between self-perceptions of ability and its influence on achievement [7], [10]. Collectively, these actions result in scholarship that offers a relatively distilled portrait of the internal factors.

\section{A New Approach: Interpretive Case Study}

What needs to be developed, therefore, is a more in-depth, sophisticated understanding that extends beyond the normative attributes and perspectives of students to comprehend who they are as a whole human beings. In my research to date, I endeavor to achieve this via interpretive case study informed by philosophical hermeneutics. The goal, as in other such studies, is to develop an understanding of how individuals experience and construct their world [5]. It is my intention to transform my understanding of the participants' experiences through dialectical engagement with participants and through identifying whole-part relationships. This interpretive approach will allow for a deep insight into the "complex world of lived experience from the point of view of those who live it" [13].

In so doing, I seek to discern key patterns and themes to develop a holistic understanding of highachieving SLD and their experiences in school. This holistic understanding has the potential to inform decisions regarding practices, pedagogy and policies, which may ultimately improve the participation of SLD in higher education - thus helping them to improve their achievement and reach their full potential. Accordingly, to address these questions, I am conducting an interpretive inquiry (specifically, a qualitative interpretive case study) guided by hermeneutics [1], [5]. This involves interviewing two female and one male academically high-achieving university students who self-identify with LD. I am developing a case study for each student before studying similarities and differences within and among the four cases. To develop the case studies, I am using the format suggested by Ellis [3]: a) an introduction or narrative portrait that offers a holistic sense of the person; b) an introduction to the site(s) i.e., the programs, institutions, times and places - in which the students' experiences occurred; c) examples of these experiences; and d) the participant's expressed views about the experiences. The interviews include four clusters of open-ended questions on the following topics to invite other memories and ideas for the participants to share: a) their lives in general; b) their earlier years; c) their earlier school experiences from kindergarten through grade 12; and d) their university experience. In a second follow-up interview the participants will be invited to say more about the experiences or ideas mentioned in the first interview.

The case studies are interpretive in emphasis [5]. This means that I am making sense of the data in part by using my preconceptions and pre-understandings, and I am using my own judgement to evaluate and improve upon the interpretations [1]. This will be a rigorous process guided and informed by key ideas and metaphors in hermeneutics. These include the identification of whole-part relationships (that is, gaining a clear understanding of the co-constituted inter-relationship between the individual and their world) [6]; heightened attention to language and discourse communities (that is, the political and historical context in which the individuals speak) [2]; and the use of the hermeneutic circle in interpretation (that is, making initial sense of the data in light of one's own interpretive framework, and later reexamining the data for gaps, inconsistencies and contradictions). Based on this analysis, I will produce a holistic account of each participant's experience in school that offers insights into the complexity of that experience, uncovering richly nuanced data that have never been accessed before.

The significance of this research lies in advancing our understanding of high-achieving students with learning disabilities in post-secondary education. Accessing the voices of these students will provide unique insight into the friction between policy, practice, and lived experience. This understanding can inform and enhance decisions regarding practices, pedagogy and policies to enable students with learning disabilities to fully participate in higher education and improve their achievement.

\section{Building Qualitative Foundations: A Call for Diversity}

The work of the researcher is only one small contribution to a field of study in need of methodologically diverse approaches for the examination of academically high-achieving SLD. These approaches should also be sensitive to who these individuals are - their educational and occupational profiles, aspects of their identity and the contexts in which they live.

\subsection{Methodological diversity}

While the diversity of methods is important, there are approaches that would be more productive in this context or for achieving the goals of rich, in-depth understanding of the experiences of SLD. In the case of ethnography or grounded theory, while these approaches are valuable in other contexts, there are arguably not optimal for the stated aims and objectives of understanding SLD. These two approaches can potentially produce a homogeneous 
view or understanding of SLD which may contribute to labelling and stigmatization, and to ineffective teaching, assessment and accommodations.

By contrast, other qualitative approaches may be better suited to access the depth and complexity of these individuals which is absent in the existing research. Interpretive approaches involve learning about the thoughts and experiences that inform human action [2]. The researcher's purpose is to work holistically to learn the thinking, feeling and the intent or meaning behind another's actions and in so doing, "come to see how their thoughts and behaviour are reasonable and coherent". Accordingly, Ellis [2] notes, the aim of interpretive research is to "develop new insight or new learning that transforms the researcher's understanding such that he or she can think more richly and act more usefully in relation to the problem or question studied". As such, the researcher uses key ideas about interpretive inquiry and in this case, those from hermeneutics, to contribute to the ongoing development and transformation of the researcher's understanding of the experiences of others and how they make meaning and sense of their lives. Interpretive case study, as described above, is one such interpretive approach.

\subsection{Contextual diversity}

This refers to different situations in which persons with LD find themselves. Contextual diversity could include, however, is not limited to national and or provincial contexts in which institutions are located, local discourses, institutional policy and makeup (e.g., secular versus religious), and elite schools versus non-research-based institutions. Are these problematic? Context thus can impact how LD are conceived of, responded to, accommodated, and how people interact with SLD. Consequently, this contributes to how meaning and significance is ascribed by those with LD.

\subsection{Intersectional diversity}

Intersectional diversity encompasses different aspects of identity that might influence or inform both the context and the ways in which SLD experience and make meaning from their lives. These aspects can include gender expression, religion, community, occupation, sex, culture, age, socioeconomic status, familial education, and ethnicity. Such rich dimensions of identity have the potential to mediate lived experience, meaning, and significance for SLD.

By addressing these new forms of diversity with new, focused research that will ask questions that have not been asked before regarding the experiences, thoughts, feelings, meaning and significance of SLD, such endeavors have the potential to offer new insights that can be used to inform legislation, policy and practice.

\section{References}

[1] Chapman, J.W., (1988). Cognitive-motivational characteristics and academic achievement of learning disabled children: A longitudinal study. Journal of Educational Psychology, 80(3), 357-365.

[2] Ellis, J. L. (1998). The teacher as interpretive inquirer. Teaching from understanding: Teacher as inquirer, J. L. Ellis, ed. New York: Garland Publishing, pp. 1-14.

[3] Ellis, J. (2006). Researching children's experiences hermeneutically and holistically. Alberta Journal of Educational Research, 52(3), 111-126.

[4] Ellis, J. (2009). Interpreting results. In A.J. Mills, G. Durepos, \& E. Weibe (Eds.), Encyclopedia of case study research (pp. 484-486). Thousand Oaks, CA: Sage.

[5] Goldberg, R., Higgins, E., Raskind, M., \& Herman, K. (2003). Predictors of success in individuals with learning disabilities: A qualitative analysis of a 20-year longitudinal study. Learning Disabilities Research and Practice, 18(4), 222-236. http://dx.doi.org/10.1111/1540-5826.00077

[6] Heiman, T., \& Precel, K. (2003). Students with learning disabilities in higher education: Academic strategies profile. Journal of learning disabilities, 36(3), 248-258.

[7] Heyman, W. B. (1990). The self-perception of a learning disability and its relationship to academic selfconcept and self-esteem. Journal of Learning Disabilities, 23(8), 472-475.

[8] Lackaye, T., Margalit, M., Ziv, O., \& Ziman, T. (2006). Comparisons of self-efficacy, mood, effort, and hope between students with learning disabilities and their non-LD-matched peers. Learning Disabilities Research \& Practice, 21(2), 111-121.

[9] Merriam, S. (1998). Case studies as qualitative research. In S. B. Merriam, Qualitative research and case study applications in education (pp. 26-43). San Francisco, CA: Jossey-Bass Publishers.

[10] Murray, C., \& Wren, C.T. (2003). Cognitive, academic, and attitudinal predictors of the grade point averages of college students with learning disabilities. Journal of Learning Disabilities, 36, 407-415.

[11] Patterson, M. E., \& Williams, D. R. (2002). Collecting and analyzing qualitative data: Hermeneutic principles, methods, and case examples. Champaign, IL: Sagamore Publishing.

[12] Paul, S. (2000) Students with disabilities in higher education: a review of the literature, College Student Journal, 34, 200-210.

[13] Schwandt, T. A. (2003). Three epistemological stances for qualitative inquiry: Interpretivism, 
hermeneutics, and social constructionism. In N. K. Denzin \& Y. S. Lincoln (Eds.), The landscape of qualitative research (2 ed., pp. 292-331). Thousand Oaks, CA: Sage Publications.

[14] Skinner, M. E. (1999). Characteristics of "successful" and "unsuccessful" college students with learning disabilities. Paper presented at the annual convention of the Council for Exceptional Children, Charlotte, NC.

[15] Statistics Canada. (2012). Canadian survey on disability 2012: Tables (Part II). Catalogue no.89-628-X no. 014. Retrieved from http://www.statcan.gc.ca/pub/89654-x/89-654-x2014003-eng.htm.

[16] Troiano, P. (2003). College Students and Learning Disability: Elements of Self-Style. Journal of College Student Development, 44(3), 404-419. doi: 10.1353/csd.2003.0033.

[17] Zheng, C., Gaumer Erickson, A., Kingston, N. M., \& Noonan, P. M. (2014). The relationship among selfdetermination, self-concept, and academic achievement for students with learning disabilities. Journal of Learning Disabilities, 47(5), 462-474. 